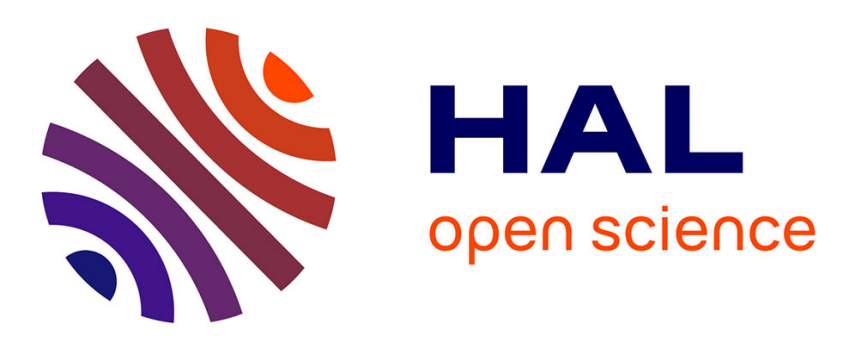

\title{
Wheat modeling in Morocco unexpectedly reveals predominance of photosynthesis versus leaf area expansion plant traits
}

Roberto Confalonieri, Simone Bregaglio, Giovanni Cappelli, Caterina Francone, Marta Carpani, Marco Acutis, Mohamed Aydam, Stefan Niemeyer, Riad Balaghi, Qinghan Dong

\section{To cite this version:}

Roberto Confalonieri, Simone Bregaglio, Giovanni Cappelli, Caterina Francone, Marta Carpani, et al.. Wheat modeling in Morocco unexpectedly reveals predominance of photosynthesis versus leaf area expansion plant traits. Agronomy for Sustainable Development, 2013, 33 (2), pp.393-403. 10.1007/s13593-012-0104-y . hal-01201349

\section{HAL Id: hal-01201349 \\ https://hal.science/hal-01201349}

Submitted on 17 Sep 2015

HAL is a multi-disciplinary open access archive for the deposit and dissemination of scientific research documents, whether they are published or not. The documents may come from teaching and research institutions in France or abroad, or from public or private research centers.
L'archive ouverte pluridisciplinaire HAL, est destinée au dépôt et à la diffusion de documents scientifiques de niveau recherche, publiés ou non, émanant des établissements d'enseignement et de recherche français ou étrangers, des laboratoires publics ou privés. 


\title{
Wheat modeling in Morocco unexpectedly reveals predominance of photosynthesis versus leaf area expansion plant traits
}

\author{
Roberto Confalonieri • Simone Bregaglio • \\ Giovanni Cappelli • Caterina Francone • \\ Marta Carpani - Marco Acutis • Mohamed El Aydam • \\ Stefan Niemeyer $\cdot$ Riad Balaghi $\cdot$ Qinghan Dong
}

Accepted: 25 June 2012 /Published online: 1 August 2012

(C) INRA and Springer-Verlag, France 2012

\begin{abstract}
This report shows the results of the first multiyear spatially distributed sensitivity analysis carried out on two complex agroecological models. Wheat is the staple food of 1.5 billion people worldwide. Projected trends in wheat global demand reveal risks of food security over the next decades. Systems for large-area crop monitoring and yield forecasting are needed to support agricultural policies, especially in developing countries. Among those crop systems, the most sophisticated ones are based on crop simulation models. Published reports of sensitivity analyses performed on different crop models show that parameters related to leaf area expansion are often considered as the most important. Here we show that, on the contrary, photosynthesis parameters are more relevant under the conditions explored. We carried out the sensitivity analysis on the
\end{abstract}

R. Confalonieri $(\bowtie) \cdot \mathrm{S}$. Bregaglio $\cdot$ G. Cappelli $\cdot$ C. Francone $\cdot$ M. Carpani $\cdot$ M. Acutis

Department of Plant Production, Università degli Studi di Milano, via Celoria 2,

20133 Milan, Italy

e-mail: roberto.confalonieri@unimi.it

M. El Aydam $\cdot$ S. Niemeyer

AGRI4CAST Action, Institute for Environment and Sustainability, Joint Research Centre, European Commission,

via Fermi 2749, TP 483,

21027 Ispra, Varese, Italy

\section{R. Balaghi}

Department of Environment and Natural Resources, Institut National de la Recherche Agronomique,

Avenue Hassan II,

Rabat, Morocco

Q. Dong

Flemish Institute for Technological Research (VITO),

Boeretang 200,

2400 Mol, Belgium models WOFOST and CropSyst for wheat simulation in Morocco. Due to the high number of model runs to be performed, a two-step procedure was adopted: The Morris method was used to identify parameters with a negligible effect, and then the Sobol method was applied on remaining parameters. Environmental and management information were obtained from the European Commission MARS database. Our results show that photosynthesis parameters explained more than $75 \%$ of the total output variance for CropSyst and more than $70 \%$ for WOFOST. On the contrary, parameters related to leaf area expansion were less relevant. Geographical patterns shown by sensitivity analysis results under heterogeneous conditions can help breeders to select specific plant traits, in order to develop phenotypes suitable for specific conditions, e.g., varieties with a higher level of thermal adaptation in the Southern regions.

Keywords CropSyst - WOFOST - Morris method - Sobol' method $\cdot$ Crop monitoring $\cdot$ Yield forecasting

\section{Introduction}

Wheat is one of the most important food crops, characterized by a chemical composition particularly suited for a variety of processed products (Ross et al. 1987). This feature and the adaptability to very heterogeneous agroclimatic conditions explain its wide geographical distribution (Mohapatra and Rao 2005). During 2008-2010, wheat has been the fourth crop worldwide in terms of production, with 674 million tons produced over 217 million ha (http://faostat.fao.org); it is the staple food of 1.5 billion people (Nguyen 2009), leading to a global market demand of about 666 million tons in 2010. A growing trend in wheat demand, i.e., $1 \%$ per year, is forecasted for the next two decades (FAO 2006), whereas observed yields 
leveled off in the last 10 years in several producing countries (Lin and Huybers 2012). This trends and the general increase in cereal prices expose to food security risks, especially in developing countries (FAO 2006).

In recent years, different typologies of systems for crop yield forecasting have been proposed, which differ with regard to techniques adopted, to the spatial scale considered, and to the sources of information used (Rojas et al. 2005). They range from simple systems based on extensive field surveys to complex ones aimed at working at continental scale by integrating different sources of information. Some of the most simple crop yield forecasting systems are based on empirical relationships between remotely sensed vegetation indices and historical series of yield data (e.g., Mkhabela et al. 2005). Other approaches are based on biophysical simulation models, where species-specific (e.g., Bannayan and Crout 1999) or generic (e.g., Soler et al. 2007) crop simulators are used. The most sophisticated crop monitoring and forecasting systems are based on the combined use of data simulated by crop models and information derived from remote sensing (e.g., Genovese et al. 2001).

In the systems implementing crop models, their proper parameterization is crucial to get a satisfactory adherence of the simulated to the real system, thus providing reliable monitoring and yield estimates. Parameter sets can be defined by using observations, in case parameters have a morphological or physiological meaning, i.e., they can be measured in or estimated from experiments in growth chambers or fields. If parameters are not measurable or if observations are not available, or when models have a high number of parameters, their values are usually defined by performing calibrations aimed at minimizing the differences between observed and simulated crop state variables, e.g., aboveground biomass, leaf area index. In this case, it is important to preliminarily identify the parameters with the highest relevance on synthetic model outputs, therefore those on which to concentrate the efforts during the calibration process. Moreover, analyzing in a quantitative way how models behavior changes according to different environmental conditions would provide an extension of model documentation, which is an essential part of the development of a biophysical model.

The identification of the most relevant model parameters, as well as the analysis of their variation patterns (Tarantola and Saltelli 2003), can be effectively carried out using advanced Monte Carlo-based sensitivity analysis techniques (e.g., Confalonieri 2012). In case the evaluation has to be carried out in large areas, sensitivity analyses should be multi-year to avoid seasonal-specific effects and spatially distributed to properly account for the spatial heterogeneity of the conditions explored. The importance of sensitivity analysis as a tool for assessing biophysical models led to its introduction in guidelines for model development (e.g.,
Jakeman et al. 2006) to the point to consider sensitivity analysis as a prerequisite for model use and calibration (Ratto et al. 2001).

The objective of this study is to carry out multi-year, spatially distributed sensitivity analyses on two worldwide used crop models, i.e., WOFOST and CropSyst, as the first step to develop a multi-model system for wheat monitoring and yield forecasting in Morocco (Fig. 1). Next steps will be the calibration of parameter sets for groups of varieties with similar features under potential and water limiting conditions and the adaptation of approaches for the simulation of biotic and a-biotic injuries to be coupled with the crop models. Sensitivity analysis results are analyzed also in light of their capability to provide support for in silico phenotyping of wheat in the study area. According to the authors, this is the first time an extensive, large-area, Monte Carlo-based sensitivity analysis study is carried out with the aims of analyzing and comparing the behavior of two complex biophysical models.

\section{Materials and methods}

\subsection{The study area}

Wheat in Morocco is grown in a variety of agroecological zones, surrounded by the Mediterranean and the Atlantic Ocean on the North and West, respectively, and by the Sahara on the southeast, with the Western High Atlas to define a mountainside region on the South of the wheatcropped area. Agroecological conditions are favorable in the rainfed, northwestern regions, whereas southeastern areas are very dry, characterized by warm winters and - wherever possible-irrigated. Rainfall during the wheat growing season, i.e., September to May, increases with latitude, ranging from $250 \mathrm{~mm}$ in the south to more than $1,000 \mathrm{~mm}$ in the northern regions. The soils are mainly loam and sandy-clay

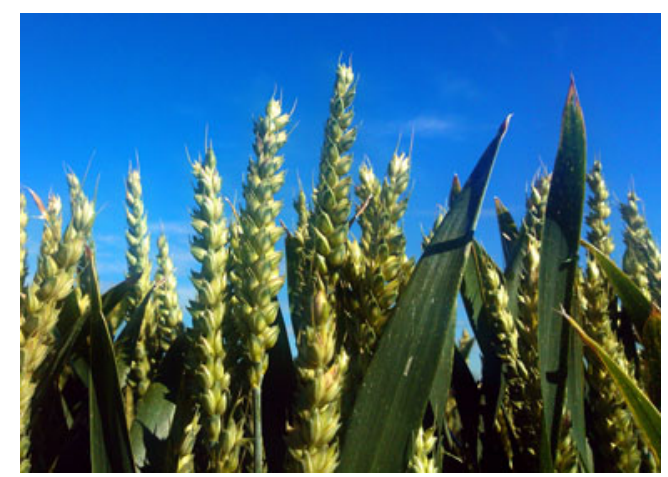

Fig. 1 Soft wheat is one of the major food crops worldwide and Morocco is ranked 24th among the world producing countries, with yields (5-year average) ranging from 0.5 to 2.4 tha $^{-1}$ in the different provinces 
loam, with a low to very low organic matter content; in the northeastern part of the country, soils present higher nutrient contents and good drainage values. Major factors limiting wheat production include drought, terminal heat stress, Hessian fly, and different fungal pathogens (e.g., Septoria, Helmintosporium, Puccinia). Grown varieties are drought tolerant and in many cases resistant to Septoria and Hessian fly; they are characterized by longer cycles and higher potential in the northwestern part of the country.

\subsection{The crop models}

The two crop models analyzed are CropSyst (Stöckle et al. 2003) and WOFOST (Van Keulen and Wolf 1986). They were selected in order to explore the responses of two very diverse approaches for the simulation of most of the processes related to crop growth and development, for the amount of data needed as input, and for their degrees of complexity, robustness, and balance (Confalonieri et al. 2010b). A summary on how the two models reproduce the main processes involved with crop growth and development is presented in Table 1 .

CropSyst estimates daily biomass accumulation by using the minimum between two approaches based on the concept of net photosynthesis. The first one is based on a relationship between aboveground biomass, potential transpiration, water vapor pressure deficit, and a vapor pressure deficitcorrected transpiration use efficiency. The instability of this approach for low values of vapor pressure deficit requires the adoption of a second approach, i.e., the temperaturelimited radiation use efficiency one, when these conditions occur. Leaf area index increase is simulated on the basis of aboveground biomass, a constant specific leaf area and an empirical coefficient, without the simulation of dynamic biomass partitioning to the different plant organs. Yield is derived by multiplying the aboveground biomass at maturity by a user-specified harvest index. The death of leaves is simulated as a simple function of senescence.

WOFOST adopts a gross photosynthesis approach to calculate dry matter, with the explicit consideration of separate terms for growth and maintenance respiration. The dynamic partitioning of photosynthates is influenced by growth respiration, thus accounting for developmentspecific partitioning factors and the different efficiencies of the conversion of assimilates into the plant organs. Yield is represented by the storage organs biomass at maturity. Total photosynthetic area is derived by the sum of the photosynthetic area of leaves, stems, and storage organs, with the leaves component being calculated as a function of temperature for leaf area index values lower than one, derived from specific leaf area and development stage elsewhere. WOFOST has a three-layer canopy representation, with a spherical leaf angle distribution and leaf area index split among the layers using a Gaussian integration. Death of leaves is determined by both senescence and self-shading. Potential evapotranspiration is estimated using the approach proposed by Penman (1948), with water stress derived by actual and potential transpiration.

For both the models and for all the sensitivity analysis experiments performed, the output considered was aboveground biomass at physiological maturity, as it is (a) a synthetic representation of the culmination of numerous biophysical processes and (b) the result of all the interactions among crop parameters.

Table 1 Approaches to the simulation of the main processes of interest

\begin{tabular}{|c|c|c|}
\hline Process & CropSyst & WOFOST \\
\hline Development & $\begin{array}{l}\text { Thermal time accumulation, possibly accounting for } \\
\text { photoperiod }\end{array}$ & $\begin{array}{l}\text { Thermal time accumulation, possibly accounting for } \\
\text { photoperiod and vernalization }\end{array}$ \\
\hline Light interception & $\begin{array}{l}\text { Monolayer canopy; Lambert-Beer law based on total leaf } \\
\text { area index and a constant extinction coefficient for solar } \\
\text { radiation }\end{array}$ & $\begin{array}{l}\text { Three canopy layers, with leaf area index split among } \\
\text { them using a Gaussian integration. Direct and diffused } \\
\text { radiation explicitly considered }\end{array}$ \\
\hline Photosynthesis & $\begin{array}{l}\text { Net photosynthesis approach based on both radiation and } \\
\text { transpiration use efficiencies, with the latter corrected for } \\
\text { vapor pressure deficit. Thermal limitation to } \\
\text { photosynthesis explicitly considered only on radiation } \\
\text { use efficiency }\end{array}$ & $\begin{array}{l}\text { Gross photosynthesis derived with Gaussian integrations } \\
\text { on the instantaneous } \mathrm{CO}_{2} \text { assimilation rates computed at } \\
\text { three moments of the day and for three canopy layers. } \\
\text { Growth and maintenance respiration are simulated }\end{array}$ \\
\hline $\begin{array}{l}\text { Biomass partitioning } \\
\text { to plant organs and } \\
\text { yield formation }\end{array}$ & $\begin{array}{l}\text { Partitioning of assimilates not explicitly considered. Yield } \\
\text { derived from aboveground biomass at maturity and a } \\
\text { harvest index }\end{array}$ & $\begin{array}{l}\text { Biomass partitioned into leaves, stems and storage organs } \\
\text { according to development-dependent partitioning factors } \\
\text { and efficiencies of assimilates conversion into the } \\
\text { different organs }\end{array}$ \\
\hline Leaf area expansion & $\begin{array}{l}\text { Derived directly from aboveground biomass and two } \\
\text { parameters: a constant specific leaf area and an empirical } \\
\text { parameter }\end{array}$ & $\begin{array}{l}\text { Calculated as a function of temperature when leaf area } \\
\text { index is lower than 1; derived from specific leaf area and } \\
\text { development stage later. Photosynthetic tissues of stems } \\
\text { and storage organs are considered }\end{array}$ \\
\hline
\end{tabular}




\subsection{Sensitivity analysis methods}

Due to the high computational requirements resulting from the necessity to perform the analysis on the whole Moroccan wheat-cropped area and on two models, it was suggested to adopt a two-step procedure for sensitivity analysis. Firstly, the parameters of the two models were screened using the Morris (1991) method. Secondly, the variance-based method of Sobol' (Sobol' 1993), considered a reference in sensitivity analysis but being the most computationally expensive one, was applied to the parameters with a nonnegligible relevance according to Morris.

In this study, the evolution of the Morris (1991) method proposed by Campolongo et al. (2007) was used. In spite of its limited requirement for only a low number of model executions, the Morris method proved its effectiveness in ranking parameters according to their relevance in different sensitivity analysis comparison studies (e.g., Confalonieri et al. 2010a). The Morris method estimates the elementary effect of each parameter $x_{i}$ belonging to the $k$-dimensional vector $X=\left(x_{1}, \ldots, x_{k}\right)$ of the model parameters on which the analysis is performed. After having rescaled all variables in the $0-1$ range, $x_{i}$ is forced to assume only $p$ discrete values, i.e., levels, in the set $\{0,1 /(p-1), 2 /(p-1), \ldots, 1\}$. Assuming $\Delta$ as a multiple of $1 /(p-1)$ and $y(X)$ as the model output, an elementary effect $R_{i}\left(x_{1}, \ldots, x_{k}, \Delta\right)$ is therefore calculated as:

$$
\begin{aligned}
& R_{i}\left(x_{1}, \ldots, x_{k}, \Delta\right) \\
& \quad=\frac{y\left(x_{1}, \ldots, x_{i-1}, x_{i}+\Delta, x_{i+1}, \ldots, x_{k}\right)-y\left(x_{1}, \ldots, x_{k}\right)}{\Delta} .
\end{aligned}
$$

Mean $(\mu)$ and standard deviation $(\sigma)$ of each $R_{i}$ population are calculated, with $R_{i}$ derived by sampling the parameters hyperspace $\Omega$, defined by a $k$-dimensional $p$-level grid. $\mu$ and $\sigma$-calculated over different trajectories $(r)$-represent, respectively, the overall influence, i.e., total effect, of the parameter $x_{i}$ and non-linearities in model response or interactions with other parameters. The total number of model evaluations needed is $r(k+1)$. The evolution of this method (Campolongo et al. 2007) allowed to get the values of $\mu^{*}$ instead of $\mu$, which is the estimate of the mean of the distribution of the absolute values of the elementary effects $R_{i}$, and to apply a more efficient sampling strategy. The use of $\mu^{*}$ solves the problem of opposite signs which occur when the model is non-monotonic. The $\mu^{*}$ metric, i.e., the overall influence of each parameter, was used in this study to identify the most relevant parameters.

The variance-based method of Sobol' (Sobol' 1993) is considered a reference in sensitivity analysis studies, although it requires a huge number of model executions. It allows the simultaneous exploration of the input hyperspace through Monte Carlo or quasi Monte Carlo sampling.
According to this method, the variance of the model output is decomposed into terms of increasing dimension, i.e., partial variances, representing the contribution of single inputs - and input pairs, triplets, etc.- to the total model output uncertainty. Percentage contributions to the total variance are quantified for inputs and input interactions using a distribution of model responses. The Sobol' variance decomposition is given by:

$V(y)=\sum_{i} V_{i}+\sum_{i<j} V_{i j}+\sum_{i<j<k} V_{i j k}+\ldots+V_{12 \ldots k}$

where $V_{i}$ is the amount of variance of the model output $y$ explained by the $i$ th parameter; $V_{i j}$ is the proportion of variance due to the interaction between $i$ th and $j$ th parameters; $V_{i j k}$ is the amount of $y$ variance explained by the interaction of the $i$ th, $j$ th, and $k$ th parameters; and $k$ is the number of parameters. Sensitivity indices of different order are then calculated as $S_{i}=V_{i} / V, S_{i j}=V_{i j} / V$, etc. The sum of $S_{i}$, $S_{i j}, \ldots$ represents the total order effect for the $i$ th parameter $\left(S t_{i}\right)$. This measure, i.e., the Sobol' total sensitivity index, was used in this study, to account for all the possible interactions of a parameter with the others (Saltelli 2002).

\subsection{Sensitivity analysis experiments}

Information on weather data and crop management were extracted from the MARS database (European Communities 2008 ), at a $25 \times 25-\mathrm{km}$ resolution. For both the Morris and Sobol' methods, the generation of samples of possible combinations of crop parameters was carried out using the SimLab dynamic link library (SimLab 2009). SimLab was used as well for the computation of the sensitivity indices from simulation results. For this study, we considered only crop parameters directly involved with crop growth, i.e., in the processes related with photosynthesis, partitioning of assimilates, leaf area evolution, and senescence. We decided to exclude soil water balance and thus model parameters involved with water stress since: (a) Wheat in the central and southeastern regions of Morocco is often irrigated and the uncertainty in the use of automatic irrigation procedures in simulations would have compromised the quality of the analysis; (b) the high relevance of the parameters involved with water stress would have surely penalized the discriminating capability of the analysis for the other parameters. Moreover, the importance of drought-tolerance traits - and related model parameters - is already well-known when crops are grown in arid and semiarid regions.

The parameters probability distributions, needed by both sensitivity analysis methods to compute the sensitivity measures considered, i.e., Morris overall influence and Sobol' total order effect in this study, were derived from literature (Tables 2 and 3). Means and standard deviations were calculated for each parameter after the application of the Shapiro-Wilk test 
Table 2 Crop parameters of CropSyst and statistical settings used for the sensitivity analysis assessment

\begin{tabular}{lllll}
\hline Parameter & Units & $\mu$ & $\sigma$ & Source \\
\hline Biomass transpiration coefficient (BTR) & $\mathrm{kPa} \mathrm{kg} \mathrm{m}^{-3}$ & 5.8 & 3.1 & Bechini et al. (2006) \\
Radiation use efficiency (RUE) & $\mathrm{g} \mathrm{MJ}^{-1}$ & 3.1 & 0.3 & Bechini et al. (2006); Kiniry et al. (1989); Stöckle et al. (1994) \\
Specific leaf area (SLA) & $\mathrm{m}^{2} \mathrm{~kg}^{-1}$ & 25 & 1.7 & Bechini et al. (2006) \\
Stem/leaf partition coefficient (SLP) & - & 1.5 & 0.08 & Bechini et al. (2006) \\
Leaf duration (LeafDur) & ${ }^{\circ} \mathrm{C}$ day & 900 & 65 & Bechini et al. (2006) \\
Extinction coefficient for solar radiation $(k)$ & - & 0.48 & 0.022 & Bechini et al. (2006); Stöckle et al. (1994) \\
Base temperature (Tbase) & ${ }^{\circ} \mathrm{C}$ & -1 & 0.05 & Bechini et al. (2006); Slafer and Rawson (1995) \\
Optimum temperature (Topt) & ${ }^{\circ} \mathrm{C}$ & 19 & 1 & Bechini et al. (2006); Slafer and Rawson (1995) \\
Initial leaf area index (LAIini) & $\mathrm{m}^{2} \mathrm{~m}^{-2}$ & 0.011 & 0.001 & Bechini et al. (2006); Stöckle et al. (1994) \\
Full canopy coefficient (Kc) & - & 1.05 & 0.07 & Bechini et al. (2006) \\
Maximum leaf area index (LAImax) & $\mathrm{m}^{2} \mathrm{~m}^{-2}$ & 7 & 0.5 & Bechini et al. (2006); Stöckle et al. (1994) \\
\hline
\end{tabular}

(Shapiro and Wilk 1965) for guaranteeing the normality of the distributions. To avoid a sampling of incoherent parameters values, i.e., in the tails of the normal distribution curve, the domain of each parameter was limited by truncations at the 10th and 90th percentiles.

To limit the seasonal-specific effect on sensitivity analysis results, 10-year simulations were run and their results were averaged. These averaged model outputs were then used to calculate the sensitivity measures.

In Table 3, the values of some parameters are referred to specific development stage codes or average air daily temperature values, e.g., light use efficiency at average air temperature equal to $10{ }^{\circ} \mathrm{C}$. This is because some of the WOFOST parameters are defined for different development stages or temperature values. Each of this these parameter is thus represented by a user-specified number of pairs [development stage, parameter value] or [average daily air temperature, parameter value]. In this study, the number of pairs, for which sensitivity analysis was performed, was reduced (a) to focus on the most relevant ones and (b) to avoid inconsistencies that can occur when sample values are generated during sensitivity analysis, e.g., partitioning coefficients to storage organs decreasing with development stage.

According to Confalonieri et al. (2010a), six trajectories were used for the Morris method, leading to 78 and 20410 year executions for each sensitivity analysis for CropSyst and WOFOST, respectively. The Sobol' method, applied to six parameters for CropSyst and to ten parameters for WOFOST, was parameterized to get more than 50010 year executions for each parameter (Confalonieri et al. 2010a), in turns leading to 3,584 and 5,632 10-year executions for each sensitivity analysis, respectively. According to a standard practice, the parameters on which applying the Sobol' method were identified by ordering all the parameters analyzed according to the Morris overall influence and by identifying discontinuities in the decreasing value of the
Morris metric. Sensitivity analysis experiments were carried out on each of the $33325 \times 25-\mathrm{km}$ grid cells resulting from the Moroccan wheat mask. The total number of sensitivity analysis experiments was 1,332, corresponding to 31,628,340 model executions.

\section{Results and discussion}

We analyzed the behavior of two crop simulators to identify the parameters - and the corresponding plant traits - with the highest influence on crop growth in the different Moroccan wheat-cropped areas. The study was performed by using spatially distributed Monte Carlo-based sensitivity analysis techniques.

\subsection{CropSyst results}

Results of the sensitivity analyses carried out on CropSyst using the Morris method are shown in Fig. 2a-c. Maximum radiation use efficiency was the parameter with the highest influence on the model output considered in most of the Moroccan wheat-cropped areas (Fig. 2a), with biomass-transpiration coefficient ranking first only in the southwestern plains of the region. This pattern can be explained by considering the role of these parameters in the two approaches to daily biomass accumulation used within CropSyst. In the regions where climate is more favorable for wheat, i.e., northern areas and mountainsides in the Western High Atlas, climatic conditions lead to lower daily biomass accumulation rates calculated using the radiation use efficiency equation compared to those derived by using the vapor pressure deficit-corrected transpiration use efficiency approach.

This means that the model considers biomass accumulation as mainly driven by the radiation use efficiency approach, thus determining the highest Morris overall influence values for the parameter involved, i.e., maximum 
Table 3 Crop parameters of WOFOST and statistical settings used for the sensitivity analysis assessment

\begin{tabular}{|c|c|c|c|c|}
\hline Parameter & Units & $M$ & $\sigma$ & Source \\
\hline Leaf area index at emergence (LAIEM) & $\mathrm{m}^{2} \mathrm{~m}^{-2}$ & 0.136 & 0.006 & Van Diepen et al. (1988); Richter et al. (2010) \\
\hline Relative leaf area growth rate (RGRLAI) & $\mathrm{m}^{2} \mathrm{~m}^{-2}$ & 0.008 & 0.001 & Van Diepen et al. (1988); Richter et al. (2010) \\
\hline Specific leaf area at DVS ${ }^{\mathrm{a}}=35($ SLATB35) & $\mathrm{m}^{2} \mathrm{~kg}^{-1}$ & 22 & 1 & Van Diepen et al. (1988); Richter et al. (2010) \\
\hline Specific leaf area at DVS $=45$ (SLATB45) & $\mathrm{m}^{2} \mathrm{~kg}^{-1}$ & 19 & 1 & Van Diepen et al. (1988); Richter et al. (2010) \\
\hline Specific leaf area at DVS $=65$ (SLATB65) & $\mathrm{m}^{2} \mathrm{~kg}^{-1}$ & 17 & 1 & Van Diepen et al. (1988); Richter et al. (2010) \\
\hline Life span of leaves growing at $35^{\circ} \mathrm{C}(\mathrm{SPAN})$ & days & 35 & 1.9 & Van Diepen et al. (1988); Arora and Gajri (1998) \\
\hline Base temperature for leaves aging (Tbase) & ${ }^{\circ} \mathrm{C}$ & 0 & 0.5 & Richter et al. (2010) \\
\hline $\begin{array}{l}\text { Extinction coefficient for diffuse visible light } \\
\text { at DVS }=0 \text { (KDIFTB000) }\end{array}$ & - & 0.4 & 0.03 & Van Diepen et al. (1988); Richter et al. (2010) \\
\hline $\begin{array}{l}\text { Extinction coefficient for diffuse visible light } \\
\text { at DVS }=100 \text { (KDIFTB100) }\end{array}$ & - & 0.6 & 0.03 & Van Diepen et al. (1988); Richter et al. (2010) \\
\hline Light use efficiency at Tavg ${ }^{b}=10^{\circ} \mathrm{C}($ EFFTB10) & $\mathrm{kg} \mathrm{ha}^{-1} \mathrm{~h}^{-1} \mathrm{~J}^{-1}$ & 0.45 & 0.03 & Van Diepen et al. (1988); Biernath et al. (2011) \\
\hline Light use efficiency at Tavg $=30^{\circ} \mathrm{C}($ EFFTB30) & $\mathrm{kg} \mathrm{ha}^{-1} \mathrm{~h}^{-1} \mathrm{~J}^{-1}$ & 0.45 & 0.03 & Van Diepen et al. (1988); Biernath et al. (2011) \\
\hline Maximum $\mathrm{CO}_{2}$ assimilation rate at DVS $=000($ AMAXTB000) & $\mathrm{kg} \mathrm{ha}^{-1} \mathrm{~h}^{-1}$ & 35.83 & 1.99 & Richter et al. (2010) \\
\hline Maximum $\mathrm{CO}_{2}$ assimilation rate at DVS $=200(\mathrm{AMAXTB} 200)$ & $\mathrm{kg} \mathrm{ha}^{-1} \mathrm{~h}^{-1}$ & 4.48 & 0.42 & Van Diepen et al. (1988); Richter et al. (2010) \\
\hline AMAX reduction factor at Tavg $=14{ }^{\circ} \mathrm{C}(\mathrm{TMPFTB} 14)$ & - & 0.92 & 0.06 & Richter et al. (2010) \\
\hline AMAX reduction factor at Tavg $=23^{\circ} \mathrm{C}($ TMPFTB23) & - & 1 & 0.04 & Richter et al. (2010) \\
\hline Efficiency of conversion into leaves (CVL) & $\mathrm{kg} \mathrm{kg}^{-1}$ & 0.68 & 0.03 & Van Diepen et al. (1988); Arora and Gajri (1998) \\
\hline Efficiency of conversion into storage organs (CVO) & $\mathrm{kg} \mathrm{kg}^{-1}$ & 0.71 & 0.04 & Van Diepen et al. (1988); Arora and Gajri (1998) \\
\hline Efficiency of conversion into roots (CVR) & $\mathrm{kg} \mathrm{kg}^{-1}$ & 0.69 & 0.04 & Van Diepen et al. (1988); Arora and Gajri (1998) \\
\hline Efficiency of conversion into stems (CVS) & $\mathrm{kg} \mathrm{kg}^{-1}$ & 0.66 & 0.03 & Van Diepen et al. (1988); Arora and Gajri (1998) \\
\hline $\begin{array}{l}\text { Relative increase in respiration per } 10{ }^{\circ} \mathrm{C} \\
\text { of temperature increase }(\mathrm{Q} 10)\end{array}$ & - & 2 & 0.1 & $\begin{array}{l}\text { Van Diepen et al. (1988); Richter et al. (2010); } \\
\text { Arora and Gajri (1998) }\end{array}$ \\
\hline Relative maintenance respiration rate for leaves (RML) & $\mathrm{kg} \mathrm{kg}^{-1}$ day $^{-1}$ & 0.03 & 0.001 & Van Diepen et al. (1988); Arora and Gajri (1998) \\
\hline $\begin{array}{l}\text { Relative maintenance respiration rate for storage } \\
\text { organs (RMO) }\end{array}$ & $\mathrm{kg} \mathrm{kg}^{-1}$ day $^{-1}$ & 0.01 & 0.001 & Van Diepen et al. (1988); Arora and Gajri (1998) \\
\hline Relative maintenance respiration rate for roots (RMR) & $\mathrm{kg} \mathrm{kg}^{-1}$ day $^{-1}$ & 0.015 & 0.001 & Van Diepen et al. (1988); Arora and Gajri (1998) \\
\hline Relative maintenance respiration rate for stems (RMS) & $\mathrm{kg} \mathrm{kg}^{-1}$ day $^{-1}$ & 0.015 & 0.001 & Van Diepen et al. (1988); Arora and Gajri (1998) \\
\hline Total biomass to roots at DVS $=0$ (FRTB000) & $\mathrm{kg} \mathrm{kg}^{-1}$ & 0.5 & 0.02 & $\begin{array}{l}\text { Van Diepen et al. (1988); Richter et al. (2010); } \\
\text { Rötter et al. (2011) }\end{array}$ \\
\hline Total biomass to roots at DVS $=100($ FRTB100) & $\mathrm{kg} \mathrm{kg}^{-1}$ & 0.02 & 0.01 & $\begin{array}{l}\text { Van Diepen et al. (1988); Richter et al. (2010); } \\
\text { Rötter et al. (2011) }\end{array}$ \\
\hline $\begin{array}{l}\text { Aboveground dry matter to leaves at DVS }=0 \\
\text { (FLTB000) }\end{array}$ & $\mathrm{kg} \mathrm{kg}^{-1}$ & 0.65 & 0.03 & $\begin{array}{l}\text { Van Diepen et al. (1988); Richter et al. (2010); } \\
\text { Rötter et al. (2011) }\end{array}$ \\
\hline $\begin{array}{l}\text { Aboveground dry matter to leaves at DVS }=50 \\
\text { (FLTB050) }\end{array}$ & $\mathrm{kg} \mathrm{kg}^{-1}$ & 0.5 & 0.03 & $\begin{array}{l}\text { Van Diepen et al. (1988); Richter et al. (2010); } \\
\text { Rötter et al. (2011) }\end{array}$ \\
\hline $\begin{array}{l}\text { Aboveground dry matter to storage organs } \\
\text { at DVS }=82 \text { (FOTB082) }\end{array}$ & $\mathrm{kg} \mathrm{kg}^{-1}$ & 0 & 0.01 & $\begin{array}{l}\text { Van Diepen et al. (1988); Richter et al. (2010); } \\
\text { Rötter et al. (2011) }\end{array}$ \\
\hline $\begin{array}{l}\text { Aboveground dry matter to storage organs } \\
\text { at DVS }=100 \text { (FLTB100) }\end{array}$ & $\mathrm{kg} \mathrm{kg}^{-1}$ & 1 & 0.07 & $\begin{array}{l}\text { Van Diepen et al. (1988); Richter et al. (2010); } \\
\text { Rötter et al. (2011) }\end{array}$ \\
\hline Specific stem area at DVS $=30($ SSATB030 $)$ & $\mathrm{m}^{2} \mathrm{~kg}^{-1}$ & 3 & 1 & Van Diepen et al. (1988); Richter et al. (2010) \\
\hline Specific stem area at DVS $=120($ SSATB120) & $\mathrm{m}^{2} \mathrm{~kg}^{-1}$ & 3 & 1 & Van Diepen et al. (1988); Richter et al. (2010) \\
\hline Specific stem area at DVS $=150($ SSATB150) & $\mathrm{m}^{2} \mathrm{~kg}^{-1}$ & 1 & 1 & Van Diepen et al. (1988); Richter et al. (2010) \\
\hline
\end{tabular}

${ }^{a}$ Development stage code (unitless; 0: emergence, 100: flowering, 200: physiological maturity)

${ }^{\mathrm{b}}$ Average air daily temperature (in degree Celsius)

radiation use efficiency. The reason for the inversion of the importance of maximum radiation use efficiency and biomass-transpiration coefficient observed in the warmest parts of the wheat-cropped area is related to the high vapor pressure deficit values, leading to low transpiration-based daily biomass accumulation rates.

To a large extent, the spatial representation of the secondranked parameters according to the Morris overall influence
(Fig. 2b) reflects what was discussed for the first-ranked ones. In fact, optimum temperature for growth played a key role in the areas where maximum radiation use efficiency was the most relevant parameter, since CropSyst accounts for thermal limitations to photosynthesis only in the radiation use efficiency approach. In the same way, full canopy crop coefficient was usually ranked second in the areas where biomass-transpiration coefficient was ranked first, 

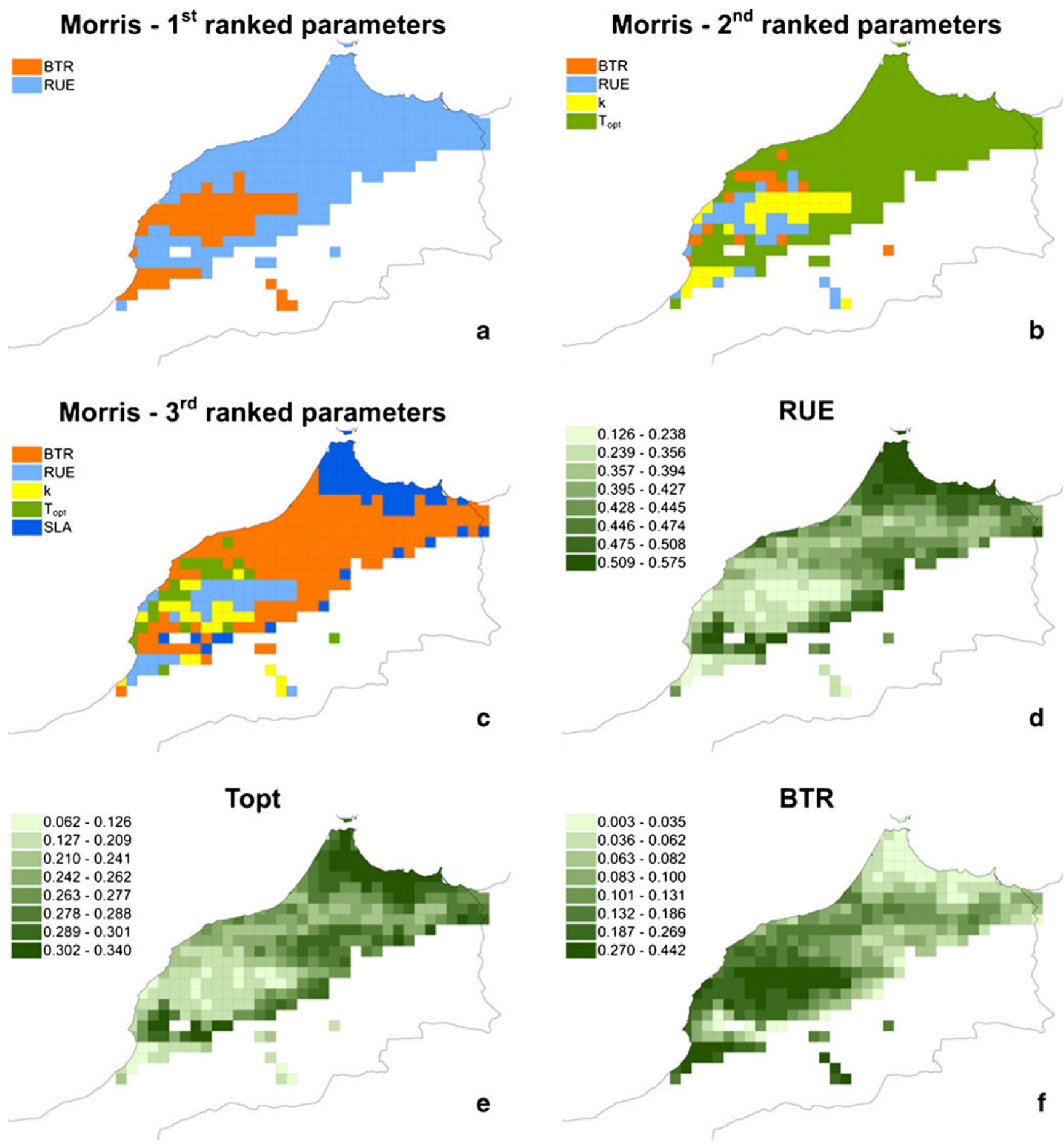

Fig. 2 Results of the spatially distributed sensitivity analyses of CropSyst. a-c Spatial distribution of first-, second-, and third-ranked parameters according to the Morris method; $\mathbf{d}-\mathbf{f}$ fraction of output variance explained by the first-, second-, and third-ranked parameters according to the Sobol' method. Parameters directly involved with photosynthesis are the most relevant, with those used within the radiation use efficiency approach, i.e., maximum radiation use efficiency (RUE)

since it is directly involved with the estimation of crop evapotranspiration, successively used to derive potential transpiration, the driving force within the vapor pressure and optimum temperature for growth (Topt), playing a key role in the most favorable regions. Biomass-transpiration coefficient $(B T R)$ reveals the predominance of the transpiration-based approach to photosynthesis elsewhere. Parameters involved with canopy structure and evolution, i.e., extinction coefficient and specific leaf area $(S L A)$, present a lower importance

deficit-corrected transpiration-based approach. Maximum radiation use efficiency and biomass-transpiration coefficient were ranked second at the borders of the two regions 
identified in Fig. 2a, which can be considered transitional areas in light of the CropSyst aptitude to be either radiation or transpiration driven.

The relevance of the parameters maximum radiation use efficiency, biomass-transpiration coefficient, optimum temperature for growth, and full canopy crop coefficient (Fig. 2a, b) is demonstrated by the fact that they are largely present also in the third-ranked parameters map (Fig. 2c), with the only exception represented by specific leaf area, playing a key role in the Mediterranean part of the Moroccan wheatcropped area.

The values of Morris overall influence for maximum radiation use efficiency, optimum temperature, biomass-transpiration coefficient, full canopy coefficient, specific leaf area, and extinction coefficient for solar radiation were clearly higher than those of the other parameters. This leads to the identification of a point of discontinuity, which allowed (a) to focus on these parameters in the Sobol'-based second step of the analysis and (b) to exclude the other model parameters resulting as not relevant under the conditions explored.

Results of the analyses carried out on the CropSyst model using the Sobol' method are shown in Fig. 2d-f, in which the spatial patterns of the Sobol' total order effect for the three top-ranked parameters, together explaining more than $75 \%$ of the total output variance, are shown. Maximum radiation use efficiency was the parameter with the highest overall relevance on CropSyst aboveground biomass accumulation (Fig. 2d), with on average about $40 \%$ of the total output variance explained in the study area. The relevance of this parameter clearly reproduced a climatic pattern driven by temperature, with the highest values of the sensitivity metric achieved in the northern part of the country and close to the western part of the High Atlas.

The parameter which ranked second according to Sobol' was optimum temperature for growth (Fig. 2e). The fact that the spatial pattern for the relevance of this parameter is very similar to that discussed for maximum radiation use efficiency reflects - as already discussed for the Morris method - the explicit presence of a thermal limitation only in the radiation-based approach for biomass accumulation within CropSyst. The importance of optimum temperature in the same cells where maximum radiation use efficiency is more relevant reflects the fact that the two parameters are strictly correlated in the simulation of the same process.

The spatial distribution of the Sobol' total order effect for biomass-transpiration coefficient was largely complementary to that shown for radiation use efficiency (Fig. 2f). This is explained by the fact that radiation use efficiency and biomass-transpiration coefficient are the main parameters involved in the two approaches for biomass accumulation and that the relationships involved are linear, with the two parameters directly multiplying the respective meteorological driving variables, i.e., absorbed solar radiation in one case and potentially transpired water in the other one. This means that when one of the two approaches for biomass accumulation is adopted, the parameter directly involved in that process becomes more relevant and vice versa. In the specific conditions explored for wheat in Morocco, the high values of vapor pressure deficit occurring in the warmest regions cause CropSyst to simulate lower transpiration-based daily photosynthetic rates compared to the radiation-based ones, thus selecting the vapor pressure deficit-corrected transpiration use efficiency law in those areas.

\subsection{WOFOST results}

Figure $3 \mathrm{a}-\mathrm{c}$ presents the results of the analyses carried out on the WOFOST model using the Morris method. Maximum $\mathrm{CO}_{2}$ assimilation rate at emergence was the most relevant parameter in most of the Moroccan wheat-cropped areas (Fig. 3a), although efficiency of conversion into storage organs assumed the highest overall influence values in the northeastern region close to the Mediterranean. The importance of these two parameters in influencing WOFOST outputs was already observed in other studies (Confalonieri 2010a; Ceglar et al. 2011), although the diverse crops simulated and the specific explored weather conditions led to different rankings among the parameters. In particular, Ceglar et al. (2011) obtained - for maize - higher sensitivity indices for the parameters involved with leaf area expansion.

The importance of maximum assimilation rate at emergence and efficiency of conversion into storage organs is underlined by the fact that they were also the second ranked in most of the $25 \times 25-\mathrm{km}$ cells: When one was the first, the other was the second (Fig. 3b). In few cells, only the parameters involved with thermal limitation to photosynthesis, i.e., the reduction factor of maximum assimilation at average daily temperature of 14 and $23{ }^{\circ} \mathrm{C}$, were ranked second.

Among the parameters ranked third according to the Morris overall influence (Fig. 3c), reduction factor of assimilation at $23{ }^{\circ} \mathrm{C}$ played a key role in the southern part of the Moroccan wheat-cropped area, where air temperature is often higher than the thermal requirements of the crop. In the northern part of the country, from the Tensift River to the Mediterranean, the third-ranked parameter was predominantly light use efficiency at average air daily temperature equal to $10{ }^{\circ} \mathrm{C}$.

Apart from maximum assimilation rate at emergence and efficiency of conversion into storage organs, which result as the parameters with the highest overall influence on the output considered, it was thus possible to identify another group of relevant parameters, i.e., light use efficiency at $10{ }^{\circ} \mathrm{C}$, reduction factor of assimilation at 14 and $23^{\circ} \mathrm{C}$, partitioning to roots at emergence, relative increase in respiration rate per $10^{\circ} \mathrm{C}$ of temperature increase, efficiency of conversion into leaves, light use efficiency at $30^{\circ} \mathrm{C}$, and specific leaf area at development stage code equal to 35 . These parameters, which 

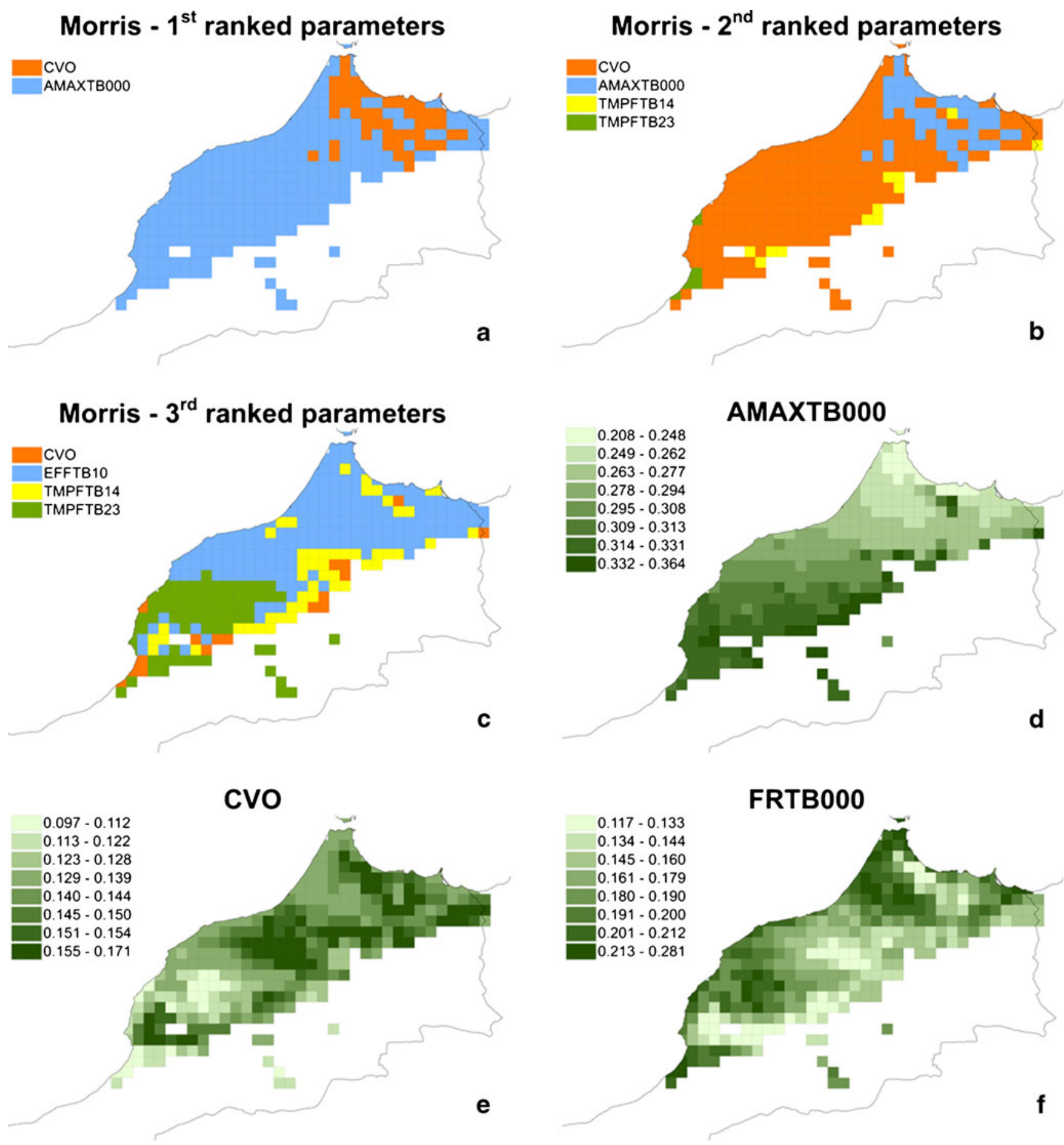

Fig. 3 Results of the spatially distributed sensitivity analyses of WOFOST. a-c Spatial distribution of first-, second-, and third-ranked parameters according to the Morris method; $\mathbf{d}-\mathbf{f}$ fraction of output variance explained by the first-, second-, and third-ranked parameters according to the Sobol' method. Parameters involved with photosynthesis, i.e., maximum $\mathrm{CO}_{2}$ assimilation at early stages (AMAXTB000)

and light use efficiency at $10{ }^{\circ} \mathrm{C}$ (EFFTB10), are the most important, together with those related to thermal limitation to photosynthesis (TMPFTB14, TMPFTB 23). Efficiency of conversion into storage organs $(\mathrm{CVO})$, involved with growth respiration, has a major effect in the Mediterranean regions

explain more than $60 \%$ of the total output variability in the whole Moroccan wheat-cropped area, were included in the subset selected for the second step of the analysis, performed with the Sobol' method.

Results of the analyses carried out on the WOFOST model using the Sobol' method are shown in Fig. 3d-f, which presents the values of the Sobol' total sensitivity index for the three top-ranked parameters. The influence of maximum 
assimilation rate at emergence on WOFOST output (Fig. 3d) appears to increase while moving toward warmer areas, with a north-south gradient in the sensitivity measure.

The values of Sobol' total order effect calculated for partitioning to roots at emergence (Fig. 3f) allow considering this parameter as the second most relevant according to Sobol', with a mean value of percentage output variance explained equal to $17.5 \%$; the same parameters was ranked six according to the Morris method. In this case, no clear pattern in the spatial distribution of Sobol' total order effect can be identified. A possible explanation is related with the competition for photosynthates between roots and aboveground organs - mainly leaves - in the early stages, with a direct consequence on the crop capability to rapidly cover the ground in the postemergence phase.

The third parameter according to the mean value of total order effect was efficiency of conversion into storage organs (Fig. 3e), ranked second by the Morris method. The distribution of its relevance seems to indicate three main zones: one corresponding to the areas at the north of the Tensift River, the second at the south, and the third located inside the second, in correspondence with the mountainsides in the Western High Atlas. This peculiar pattern leads to hypothesize a relationship with the thermal conditions explored.

\subsection{Parameters relevance and agro-environmental conditions}

This study demonstrates the need of carefully analyzing model behavior each time the simulated crop or the explored conditions change. Confalonieri (2010) found out that partitioning to leaves was the second most relevant parameter in influencing WOFOST behavior for rice in northern Italy and, in the same conditions, parameters such as specific leaf area, stem/leaf partition coefficient, and extinction coefficient for solar radiation were ranked from fourth to sixth in influencing CropSyst outputs. Ceglar et al. (2011) identified some of the WOFOST parameters involved in green area expansion as the most relevant for maize productivity in Slovenia. Richter et al. (2010), performing a sensitivity analysis with a wheat model very similar to WOFOST, concluded that parameters for early light interception ranked higher than those for photosynthesis in two Mediterranean sites. Contrarily to the results obtained in these studies using the same models under different conditions, here we identified the parameters involved with photosynthesis and growth respiration as the most important in influencing crop productivity. Our results are coherent with what observed in field experiments by other authors, e.g., Kobza and Edwards (1987) for temperature limitation to photosynthesis and Marcelis (1996) for a hierarchy among sinks which in turns favors the processes of partitioning/conversion to storage organs. With few exceptions, parameters directly related with leaf area expansion and canopy structure resulted less relevant throughout the study region.

\section{Conclusion}

According to the authors, this is the first time a multi-year, multi-model, spatially distributed sensitivity analysis experiment is carried out using advanced Monte Carlo techniques aimed at analyzing the relationships between models structure and environmental driving forces. This analysis allowed the attainment of an in-depth knowledge of the behavior of two crop models, thus providing rigorous elements to drive parameterization activities able to account for the heterogeneity of the conditions explored, reflecting the spatial distribution of cultivars with different morphological and physiological features. In fact, coupling the results of this study with information about the spatial distribution of groups of similar cultivars would allow the identification of the values of model parameters accounting for the suitability of a certain group of cultivars in a specific area. This would lead to the identification of "common traits" that should be considered the most relevant in that area, i.e., those explaining the reason why those cultivars are present in that region.

For both models, the parameters identified as the most relevant are mainly involved in photosynthesis and, in case of WOFOST, in respiration and the allocation of photosynthates to storage organs. Other studies carried out on the same models under different conditions and for different crops obtained discordant results, with parameters involved in leaf area expansion and canopy structure being more relevant than in our study. These results, identifying different parametersin turn corresponding to different morphological and physiological crop features - as the most relevant under different environmental conditions, could provide useful guidelines for driving the efforts of breeders toward specific plant traits, thus increasing genotype suitability for specific agroecological conditions. The overall low importance of parameters involved with canopy structure resulting from our analysis decreases the interest for genotypes improved for their capability to intercept radiation. Instead, the relevance of parameters involved with photosynthesis and thermal limitation to biomass accumulation would suggest to focus on the development of varieties with a higher level of adaptation to the thermal regimes explored in the study area, especially in the southern regions. These considerations are strengthened by the coherence of the results obtained with two models very different in the approaches adopted and in the level of detail used to reproduce plant growth.

Acknowledgments This study has been partially funded under the EU FP7 collaborative project, grant agreement $N^{\circ} 270351$, Crop monitoring as an E-agriculture tool in developing countries (E-Agri). We gratefully thank C. Aspinall and I. Cerrani (JRC, IES, MARS Unit) for the support provided. 


\section{References}

Arora VK, Gajri PR (1998) Evaluation of a crop growth-water balance model for analysing wheat response to climate and water-limited environments. Field Crop Res 59:213-224. doi:10.1016/S03784290(98)00124-5

Bannayan M, Crout NMJ (1999) A stochastic modelling approach for real-time forecasting of winter wheat yield. Field Crop Res 62:85-95. doi:10.1016/S0378-4290(99)00008-8

Bechini L, Bocchi S, Maggiore T, Confalonieri R (2006) Parameterization of a crop growth and development simulation model at submodel components level. An example for winter wheat (Triticum aestivum L.). Environ Modell Softw 21:1042-1054. doi:10.1016/ j.envsoft.2005.05.006

Biernath C, Gayler S, Bittner S, Klein C, Högy P, Fangmeier A, Priesack E (2011) Evaluating the ability of four crop models to predict different environmental impacts on spring wheat growth in opentop chambers. Eur J Agron 35:71-82. doi:10.1016/j.eja.2011.04.001

Campolongo F, Cariboni J, Saltelli A (2007) An effective screening design for sensitivity analysis of large models. Environ Modell Softw 22:1509-1518. doi:10.1016/j.envsoft.2006.10.004

Ceglar A, Črepinšek Z, Kajfež-Bogataj L, Pogačar T (2011) The simulation of phenological development in dynamic crop model: the Bayesian comparison of different methods. Agr Forest Meteorol 151:101-115. doi:10.1016/j.agrformet.2010.09.007

Confalonieri R (2010) Monte Carlo based sensitivity analysis of two crop simulators and considerations on model balance. Eur $\mathrm{J}$ Agron 33:89-93. doi:10.1016/j.eja.2010.03.004

Confalonieri R (2012) Combining a weather generator and a standard sensitivity analysis method to quantify the relevance of weather variables on agrometeorological models outputs. Theor Appl Climatol 108:19-30. doi:10.1007/s00704-011-0510-0

Confalonieri R, Bellocchi G, Bregaglio S, Donatelli M, Acutis M (2010a) Comparison of sensitivity analysis techniques: a case study with the rice model WARM. Ecol Model 221:1897-1906. doi:10.1016/j.ecolmodel.2010.04.021

Confalonieri R, Bregaglio S, Acutis M (2010b) A proposal of an indicator for quantifying model robustness based on the relationship between variability of errors and of explored conditions. Ecol Model 221:960-964. doi:10.1016/j.ecolmodel.2009.12.003

European Communities (2008) CGMS version 9.2: user manual and technical documentation. JRC scientific and technical reports. Joint Research Centre, European Commission. Office for Official Publications of the European Communities. Luxembourg. doi:10.2788/37265

FAO (2006) World agriculture: towards 2030/2050. Interim report. FAO, Rome, pp 37-44

Genovese G, Vignolles C, Nègre T, Passera G (2001) A methodology for a combined use of normalized difference vegetation index and CORINE land cover data for crop yield monitoring and forecasting. A case study on Spain. Agronomie 21:91-111. doi:10.1051/agro:2001111

Jakeman AJ, Letcher RA, Norton JP (2006) Ten iterative steps in development and evaluation of environmental models. Environ Modell Softw 21:602-614. doi:10.1016/j.envsoft.2006.01.004

Kiniry JR, Jones CA, O'Toole JC, Blanchet R, Cabelguenne M, Spanel DA (1989) Radiation-use efficiency in biomass accumulation prior to grain-filling for five grain-crop species. Field Crop Res 20:51-64. doi:10.1016/0378-4290(89)90023-3

Kobza J, Edwards GE (1987) Influences of leaf temperature on photosynthetic carbon metabolism in wheat. Plant Physiol 83:69-74. doi:10.1104/pp.83.1.69

Lin M, Huybers P (2012) Reckoning wheat yield trends. Environ Res Lett 7:1-6. doi:10.1088/1748-9326/7/2/024016

Marcelis LFM (1996) Sink strength as a determinant of dry matter partitioning in the whole plant. J Exp Bot 47:1281-1291. doi:10.1093/jxb/47.Special_Issue.1281
Mkhabela MS, Mkhabela MS, Mashinini NN (2005) Early maize yield forecasting in the four agro-ecological regions of Swaziland using NDVI data derived from NOAA's-AVHRR. Agr Forest Meteorol 129:1-9. doi:10.1016/j.agrformet.2004.12.006

Mohapatra D, Rao PS (2005) A thin layer drying model of parboiled wheat. J Food Eng 66:513-518. doi:10.1016/j.jfoodeng.2004. 04.023

Morris MD (1991) Factorial sampling plans for preliminary computational experiments. Technometrics 33:161-174

Nguyen NV (2009) Ensuring food security in the 21th century with hybrid rice: Issues and challenges. In: Xie F, Hardy B (eds) Accelerating hybrid rice development. International Rice Research Institute, Los Baños, pp 9-24

Penman HL (1948) Natural evaporation from open water, bare soil and grass. Proc Royal Soc A 193:120-145. doi:10.1098/rspa.1948.0037

Ratto M, Tarantola S, Saltelli A (2001) Sensitivity analysis in model calibration. GSA-GLUE approach. Comp Phys Comm 136:212224. doi:10.1016/S0010-4655(01)00159-X

Richter GM, Acutis M, Trevisiol P, Latiri K, Confalonieri R (2010) Sensitivity analysis for a complex crop model applied to Durum wheat in the Mediterranean. Eur J Agron 32:127-136. doi:10.1016/ j.eja.2009.09.002

Rojas O, Rembold F, Royer A, Negre T (2005) Real-time agrometeorological crop yield monitoring in Eastern Africa. Agron Sustain Dev 25:63-77. doi:10.1051/agro:2004056

Ross SW, Brand JC, Thorburn AW, Truswell AS (1987) Glycemic index of processed wheat products. Am J Clin Nutr 46:631-635

Rötter RP, Palosuo T, Pirttioja NK, Dubrovsky M, Salo T, Fronzen S, Aikasalo R, Trnka M, Ristolainen A, Carter TR (2011) What would happen to barley production in Finland if global warming exceeded 4 C? A model based assessment. Eur J Agron 35:205214. doi:10.1016/j.eja.2011.06.003

Saltelli A (2002) Making best use of model evaluations to compute sensitivity indices. Comput Phys Commun 145:280-297. doi:10.1016/S0010-4655(02)00280-1

Shapiro SS, Wilk MB (1965) An analysis of variance test for normality (complete samples). Biometrika 5:591-611

SimLab v. 32.5 Documentation (2009) POLIS-JRC/ISIS, Ispra, Italy http://simlab.jrc.ec.europa.eu/docs/html/index.html Accessed 7 Mar 2012

Slafer GA, Rawson HM (1995) Rates and cardinal temperatures for processes of development in winter wheat: effects of temperature and thermal amplitude. Aust J Plant Physiol 22:913-926. doi:10.1071/PP9950913

Sobol' IM (1993) Sensitivity estimates for nonlinear mathematical models. Math Model Comput Exp 1:407-414

Soler CMT, Sentelhas PC, Hoogenboom G (2007) Application of the CSM-CERES-Maize model for planting date evaluation and yield forecasting for maize grown off-season in a subtropical environment. Eur J Agron 27:165-177. doi:10.1016/ j.eja.2007.03.002

Stöckle CO, Martin SA, Campbell GS (1994) CropSyst, a cropping systems simulation model: water/nitrogen budgets and crop yield. Agr Syst 46:335-359. doi:10.1016/0308-521X(94)90006-2

Stöckle CO, Donatelli M, Nelson R (2003) CropSyst, a cropping systems simulation model. Eur J Agron 18:289-307. doi:10.1016/S1161-0301(02)00109-0

Tarantola S, Saltelli A (2003) SAMO 2001: methodological advances and innovative applications of sensitivity analysis. Reliab Eng Syst Safety 79:121-122. doi:10.1016/S0951-8320(02)00221-1

Van Diepen CA, Rappoldt C, Wolf J, van Keulen H (1988) Crop growth simulation Model WOFOST. Documentation version 4 . 1. Centre for World Food Studies, Wageningen

Van Keulen H, Wolf J (1986) Modelling of agricultural production: weather soils and crops. Simulation monographs. Pudoc, Wageningen. doi:10.1016/0308-521X(87)90100-4 